\title{
Pattern and the cause circle of offence related to addictive substance use in juvenile observation and protection centers, Thailand
}

Chitlada Areesantichai, Usaneya Perngparn,

PhD, Drug Dependence Research Center, World Health Organization Collaborating Center for Research and Training in Drug Dependence (WHOCC), College of Public Health Sciences, Chulalongkorn University, Bangkok, Thailand 10330.

Correspondence: Chitlada Areesantichai.email : chitlada.a@chula.ac.th

\begin{abstract}
This cross-sectional study examines the pattern and cause circle of offence occurrences related to addictive substance use among 1002 juvenile participants (quantitative) and 52 participants (qualitative) in six juvenile observation and protection centers. The results indicated that males were more likely to use cannabis, kratom, Yaba, ecstasy, ketamine, and ice during their lifetime $(\mathrm{p}<0.05)$. The causes of offence occurrences in female juveniles mainly derived from family, whereas in male juveniles, besides their family, they (themselves) and their friends were the causes.

Juveniles who had entered the justice system after such experiences will have high risk of drug relapse and re-offence. Finding the pattern and the cause circle of offence occurrences may be beneficial to delivering interventions to resolve the gap of the cause circle before returning them to the community.
\end{abstract}

Keywords: Pattern, Cause circle, Addictive substance use, Juvenile observation and protection centers, Thailand

\section{Introduction}

Illicit drug use has been one of the most widely contributing factors associated with juvenile delinquency. ${ }^{1,2,3}$ In the United States, it is estimated that $10 \%$ of youth were addicted to illicit drug use in the past year. ${ }^{4}$ Delinquent youths are three times more likely to use a psychoactive drug than youth in the general population $^{5}$, with prevalence rates of drug use amounting to $38-85 \%$ in the past year among juvenile offenders. ${ }^{6,7}$ A recent national report examining the prevalence of drug use among juvenile delinquents revealed a substantial increase over the past 25 years. ${ }^{8}$ 
In 1997 according to statistical data of the Department of Juvenile Observation and Protection in Thailand, about $30 \%$ of children and juveniles below 18 years old committed offences of property. Of this about $16 \%-20 \%$ were related to drug abuse. ${ }^{9}$

Many studies of the College of Public Health Sciences, Chulalongkorn University (in 2003, 2005, 2006, 2007 and 2008) indicated other charges concerned with substance use. Social context, family problems and others are risk factors to juveniles' substance use. ${ }^{10-15}$

Drug users were regarded as patients and all juveniles arrested were sent to treatment control systems. Substance abuse cases decreased from 16,723 in 2002 to 5,897 in 2003. Decrease of juveniles' drug cases was for methamphetamine (Yaba) use only, while other drug charges, especially volatile substance use has risen.

Many foreign studies indicated that deviant behaviour patterns of parents and close family members were correlated with behaviour patterns of youth. Thailand is no exception, but there is no comprehensive study. This report aims to provide data to support the pattern of substance use and the causes of offence occurrences related to addictive substance use in the Juvenile Observation and Protection Centers by quantitative and qualitative analysis.

\section{Methods}

This cross-sectional study used face to face interviews for quantitative and in-depth interviews for qualitative research in 2004. Inclusion criteria were 1) substance use experience, 2) juveniles aged 11-20 years with drug charges i.e. drug use/drug possession, drug dealers and others, 3) new cases, 4) willingness to be interviewed. Exclusion criteria were 1) having psychology symptoms, 2) having depression. We used purposive sampling to select samples who met inclusion criteria, both quantitative and qualitative.

The sample size (quantitative) was calculated by using G-power program (Effect size $=0.1$, power $=80 \%$, alpha $=0.05$ ). We required at least 785 participants. Thus, $10 \%$ were added for the missing data. The sample size was 864 participants. We collected 1,002 participants from 6 juvenile centers (2 Remand Homes ( $\mathrm{n}=250)$; Samutprakan and Baan Mettas $(\mathrm{n}=654)$; Baan Mutita, Baan Karuna and Baan Ubegka ( $\mathrm{n}=98)$; Baan Pranee).

The sample size (qualitative) was selected from participants with drug charge/ drug using experience. The qualitative selection derived from two sources: individual quantitative interview and the center authorities. The qualitative sample size was 52 participants from six juvenile centers. We requested permission from all participants and provided the consent form before interviewing them. 
We explored differences in this sample's substance use by using $\chi 2$ tests for categorical measures and 95\% confidence interval.

\section{Results}

\section{Quantitative results}

\section{Demographic and social characteristics}

The average ages of male and female juveniles were 16-18 years. Over $60 \%$ males were single. About 35\% males completed grade 6 (compulsory level), whereas females completed grade 9 . About $50 \%$ of male juveniles had no employment. Sixty five percent of males and females were charged with drug peddling; Fifty percent and $60.0 \%$ males and females were charged as drug users respectively. About $30 \%$ males worked as labourers, while the employment details of females were not clearly recorded. Over half of them had no income (Table 1).

Table 1. Comparison of demographic characteristics between male $(n=888)$ and female $(n=114)$ juveniles

\begin{tabular}{lcccc}
\hline & \multicolumn{2}{c}{$\begin{array}{c}\text { Male } \\
\mathrm{n}(\%)\end{array}$} & \multicolumn{2}{c}{ Female } \\
& $\mathrm{n}(\%)$ \\
\hline Education; incomplete high school & 285 & $(32.1)$ & 32 & $(28.1)$ \\
Unemployed & 427 & $(48.1)$ & 69 & $(60.5)$ \\
Minor occupation; sold drugs* & 351 & $(39.5)$ & 76 & $(66.7)$ \\
Ever treated* & 137 & $(15.4)$ & 14 & $(12.3)$ \\
\hline
\end{tabular}

*significant of demographic characteristics among non-injection and injection group at 0.05

\section{Addictive substance use and risk behaviour}

Nineteen male juveniles and two females had experience using heroin. About $12.2 \%$ male juveniles and $13.2 \%$ female juveniles used inhalants or volatile substances such as glue. Only 3\% males used ecstasy, whereas $8.8 \%$ females ever used it. Moreover, $80 \%$ juveniles ever consumed alcohol (Table 2). 
Table 2. Pattern of drug use among male $(n=888)$ and female $(n=114)$ juvenile drug users

\begin{tabular}{lrrrrrr}
\hline Substance use & \multicolumn{2}{c}{ Male } & \multicolumn{2}{c}{ Female } & \multicolumn{3}{c}{$95 \%$} \\
& \multicolumn{1}{c}{$(\%)$} & \multicolumn{1}{c}{ (\%) } & Confidence & Interval \\
\hline Cannabis; lifetime** & 478 & $(53.8)$ & 39 & $(34.2)$ & 0.296 & 0.671 \\
Cannabis; in 1 year & 322 & $(36.3)$ & 29 & $(25.4)$ & 0.668 & 2.956 \\
Cannabis; in 1 month & 171 & $(19.3)$ & 17 & $(14.9)$ & 0.579 & 2.704 \\
Kratom; lifetime* & 76 & $(8.6)$ & 3 & $(2.6)$ & 0.09 & 0.931 \\
Kratom; in 1 year & 41 & $(4.6)$ & 3 & $(2.6)$ & 0.991 & 1.162 \\
Kratom; in 1 month & 17 & $(1.9)$ & 1 & $(0.9)$ & 0.062 & 8.765 \\
Yaba (methamphetamine); & 648 & $(73.0)$ & 71 & $(62.3)$ & 0.407 & 0.918 \\
lifetime* & 543 & $(61.1)$ & 59 & $(51.8)$ & 0.494 & 1.83 \\
Yaba; in 1 year & 391 & $(44.0)$ & 46 & $(40.4)$ & 0.723 & 2.618 \\
Yaba; in 1 month & 19 & $(2.1)$ & 2 & $(1.8)$ & 0.188 & 3.553 \\
Heroin; lifetime & 10 & $(1.1)$ & 1 & $(0.9)$ & 0.049 & 16.594 \\
Heroin; in 1 year & 6 & $(0.7)$ & 0 & $(0.0)$ & 0.516 & 1.24 \\
Heroin; in 1 month & 108 & $(12.2)$ & 15 & $(13.2)$ & 0.613 & 1.953 \\
Inhalant; lifetime & 67 & $(7.5)$ & 12 & $(10.5)$ & 0.652 & 9.195 \\
Inhalant; in 1 year & 34 & $(3.8)$ & 9 & $(7.9)$ & 0.724 & 11.71 \\
Inhalant; in 1 month & 29 & $(3.3)$ & 10 & $(8.8)$ & 1.349 & 6.011 \\
Ecstasy; lifetime* & 25 & $(2.8)$ & 7 & $(6.1)$ & 0.067 & 2.076 \\
Ecstasy; in 1 year & 16 & $(1.8)$ & 1 & $(0.9)$ & 0.01 & 0.907 \\
Ecstasy; in 1 month * & 11 & $(1.2)$ & 7 & $(6.1)$ & 1.98 & 13.74 \\
Ketamine; lifetime** & 9 & $(1.0)$ & 6 & $(5.3)$ & 0.098 & 18.192 \\
Ketamine; in 1 year & 7 & $(0.8)$ & 2 & $(1.8)$ & 0.014 & 1.444 \\
Ketamine; in 1 month & 9 & $(1.0)$ & 1 & $(0.9)$ & 0.108 & 6.886 \\
Cocaine; lifetime & 5 & $(0.6)$ & 0 & $(0.0)$ & 0.516 & 1.24 \\
Cocaine; in 1 year & 3 & $(0.3)$ & - & - & - & - \\
Cocaine; in 1 month & 4 & $(0.5)$ & 2 & $(1.8)$ & 0.715 & 21.792 \\
Domicum(Midazolam); & 2 & $(0.2)$ & 2 & $(1.8)$ & 0.751 & 5.329 \\
lifetime & 1 & $(0.1)$ & 2 & $(1.8)$ & 0.606 & 14.864 \\
Domicum; in 1 year & 146 & $(16.4)$ & 27 & $(23.7)$ & 0.989 & 2.516 \\
Domicum; in 1 month & 111 & $(12.5)$ & 24 & $(21.1)$ & 0.716 & 8.883 \\
Ice; lifetime* & 74 & $(8.3)$ & 15 & $(13.2)$ & 0.334 & 2.082 \\
Ice; in 1 year & & & & & & \\
Ice; in 1 month & & & & &
\end{tabular}

* significant at 0.05

**significant at 0.01 
Over $66 \%$ males and over $46 \%$ females have shown sexual behaviour (Table $3)$.

Table 3. Risk behaviour among male $(n=888)$ and female $(n=114)$ juvenile drug users

\begin{tabular}{lrrrrrr}
\hline & \multicolumn{2}{c}{ Male } & \multicolumn{2}{c}{ Female } & \multicolumn{2}{c}{$95 \%$} \\
& \multicolumn{1}{c}{$\mathrm{n}$} & \multicolumn{1}{c}{$(\%)$} & \multicolumn{1}{c}{$\mathrm{n}$} & \multicolumn{1}{c}{$(\%)$} & \multicolumn{2}{c}{ Confidence Interval } \\
\hline Drug injection & 32 & $(3.6)$ & 4 & $(3.5)$ & 0.338 & 2.803 \\
Have sexual behaviour & 591 & $(66.6)$ & 53 & $(46.5)$ & 0.295 & 0.647 \\
No condom use & 244 & $(27.5)$ & 28 & $(24.6)$ & 0.741 & 1.827 \\
Roaming/Prostitutes & 36 & $(4.1)$ & 4 & $(3.5)$ & 0.301 & 2.464 \\
Ever consume alcohol & 702 & $(79.1)$ & 83 & $(72.8)$ & 0.455 & 1.105 \\
\hline
\end{tabular}

**significant at 0.01

\section{Qualitative results}

\section{Results of the male juvenile group study}

Causes of offence occurrences were mostly related to addictive substances derived from three central issues:

Personal problems: beginning from the juveniles' curiosity to substance use, their roaming in entertainment places (pubs/bars), their quarrelling and fighting, and robbery

Family problems: the juveniles' broken homes, their family members' imprisonment, gambling, drug peddling and drug use including consumption of alcohol

Friends' problems: beginning from their friends' persuasion to try addictive substance and to commit crimes such as robbing

Juveniles with family problems would escape their problem by using/selling drugs or running away from home to live with their friends or relatives who were drug peddlers. This is one of the major causes that pushed them into illegal offences (such as robbery or even murder) and drug trafficking with friends, in order to earn their living. These juveniles would easily be lured for drug trafficking because of their current environment and desire to have high earning. Some juveniles regarded drug peddling as a business with a high income.

There are chances that the juveniles who are not being arrested will commit offences repeatedly. When arrested, they will be sent to a correction center. After being released, they will have two alternatives, either to lead a new life 
or to return to the same cycle of using addictive substances and committing offences (Figure 1).

Figure 1 Cause Circle of Offence related to addictive substance use in Juvenile Observation and Protection Center among male juveniles

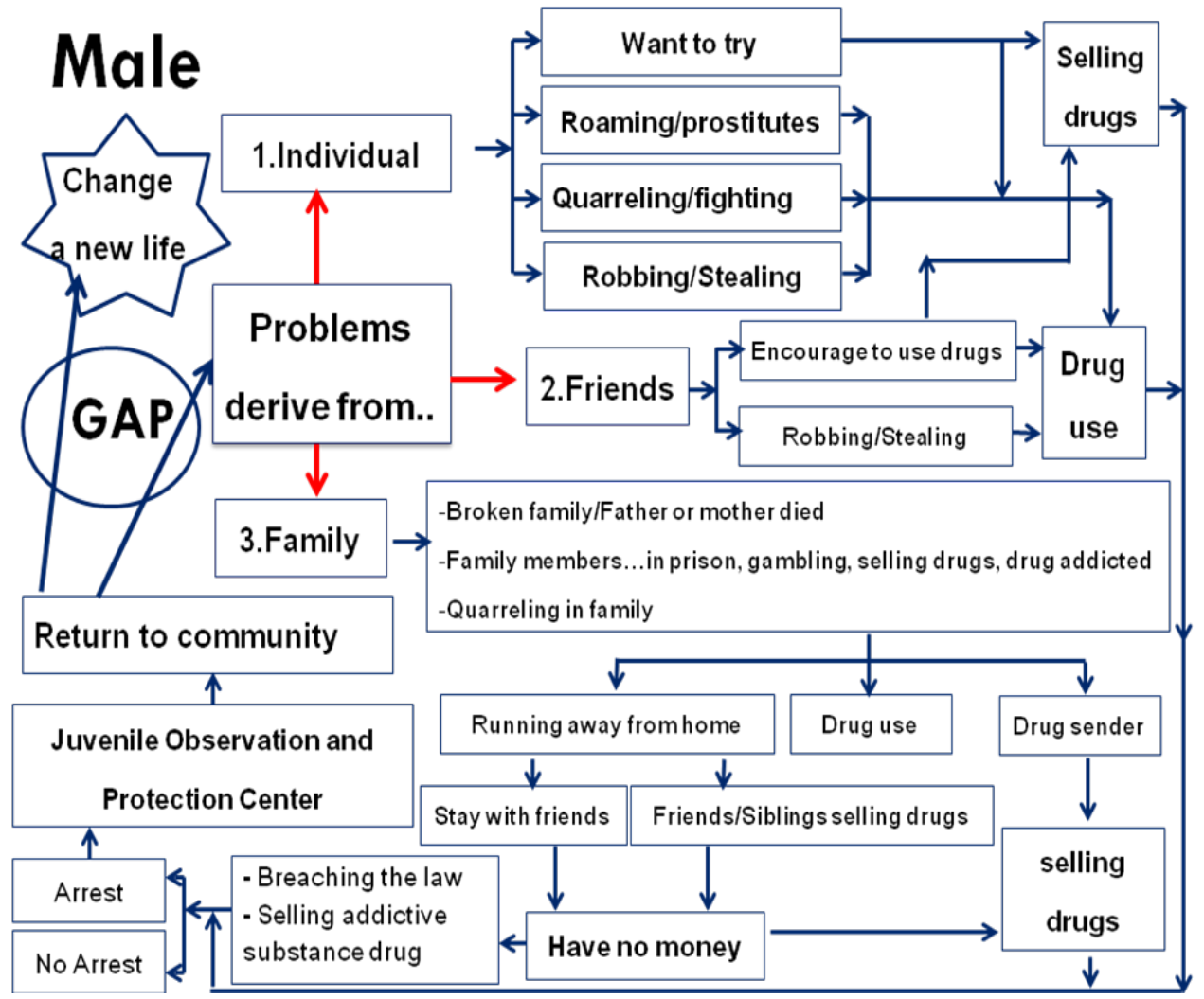

\section{Male juvenile examples}

"M1": A 20-year-old, Bangkok drug dealer. He was arrested with 3 charges: robbing, stealing, and an accomplice in stealing.

Family: Parents were separated and he lived with his friends. He reported selling Yaba when he was only seven years old because his family sold it. His older sister sniffed glue. "I've grown up with this kind of family, so what can I do? If I don't sell drugs, I won't have money to spend. If I have a bigger job such as being hired to kill someone, I'll have to stop selling Yaba for a while because I need to spend quite a time following my victim."

"M2", 18 years old, is studying fine art design in a vocational school. His hometown is in a province in the Central region. He was charged with murdering. He sold Yaba when he was 17 years old. He lives with his father's parents and parents who are quite well-off. 
He used seven types of drugs starting with Yaba when he was 15 years old, followed by opium because he saw someone in his house smoke. Then he used cannabis, heroin then ecstasy, cocaine and Ice. He said, "Taking drugs is very normal for us - Art kids. It makes us have good imagination."

"M3", 17-year-old, has completed grade 12. His house is in Klongtoey (slum area), Bangkok. He is a messenger and a drug peddler. He was charged with drug use. His father has passed away when he was a child. At present, he lives with his mother, older brother and aunt. He used almost all drugs i.e. cannabis (when 10 years old), Ice, glue, Yaba, ecstasy, ketamine and cocaine. He has been in the Yaba treatment programme for 10 times. However, he used drugs immediately after he left the center. He admitted that he was not determined enough to quit. He said, "I sell drugs as my older brother knew a big drug peddler, so I tried to sell and it's a good business, so I got from him to sell almost everything, i.e. cannabis, Yaba, glue, ecstasy, ketamine, cocaine and Ice. I sell and use a lot. You wouldn't know how good it is, until you try it. I can't describe it."

"M4", 18 years old. He got married after completing grade 8 . He was charged with selling 15 tablets of Yaba and he has been sentenced for three years. Two of his siblings were involved in Yaba charges. One in prison on Yaba use charge, and another one also used Yaba, but she was killed in a car accident. He began selling drugs when he ran away from home because he quarrelled with his father. His friends whom he stayed with, persuaded him to sell drugs. He also thought that it gives a good income. He said, "I quarrelled with my brother and I hit his arm with a knife. My father yelled at me and wouldn't listen to know why we're quarrelling. So I ran away from home to stay with my friend. My father went to fetch me so I went to stay with another friend who sold drugs. He persuaded me to sell drugs because it gives a good income. Then I didn't have money and I couldn't borrow money from him all the time. I stayed with him I had to help him sell". He said he started using cannabis (at 15 years old) then Yaba, Ice. He also mixed Yaba and Ice together as he believed it could prolong much longer.

\section{Results of the female juvenile group study}

Mostly the causes of offence occurrences began from family problems including undesirable patterns of behaviour of family members such as drug addiction/drug peddling. When family problems arise, they would decide to run away from home leading to an environment which lured them to drug peddling by two means: First, they met, lived or roamed about with their friends/boyfriends. Secondly, they knew their friends or the drug network through their friends/boyfriends who were drug peddlers. Both means led to either drug use. However, the principal point leading them to commit offences, such as drug peddling or sex services was their desire to have money for expenses after running away from home to stay with their friends, to buy 
drugs to use or to sell at a high profit. They lived with their older brothers/ sisters or friends who were drug peddlers, or who provided sex services, which facilitated them to join the drug trafficking cycle or the sex industry (Figure 2).

Figure 2 Cause circle of offence related to addictive substance use in Juvenile Observation and Protection Center among female juveniles

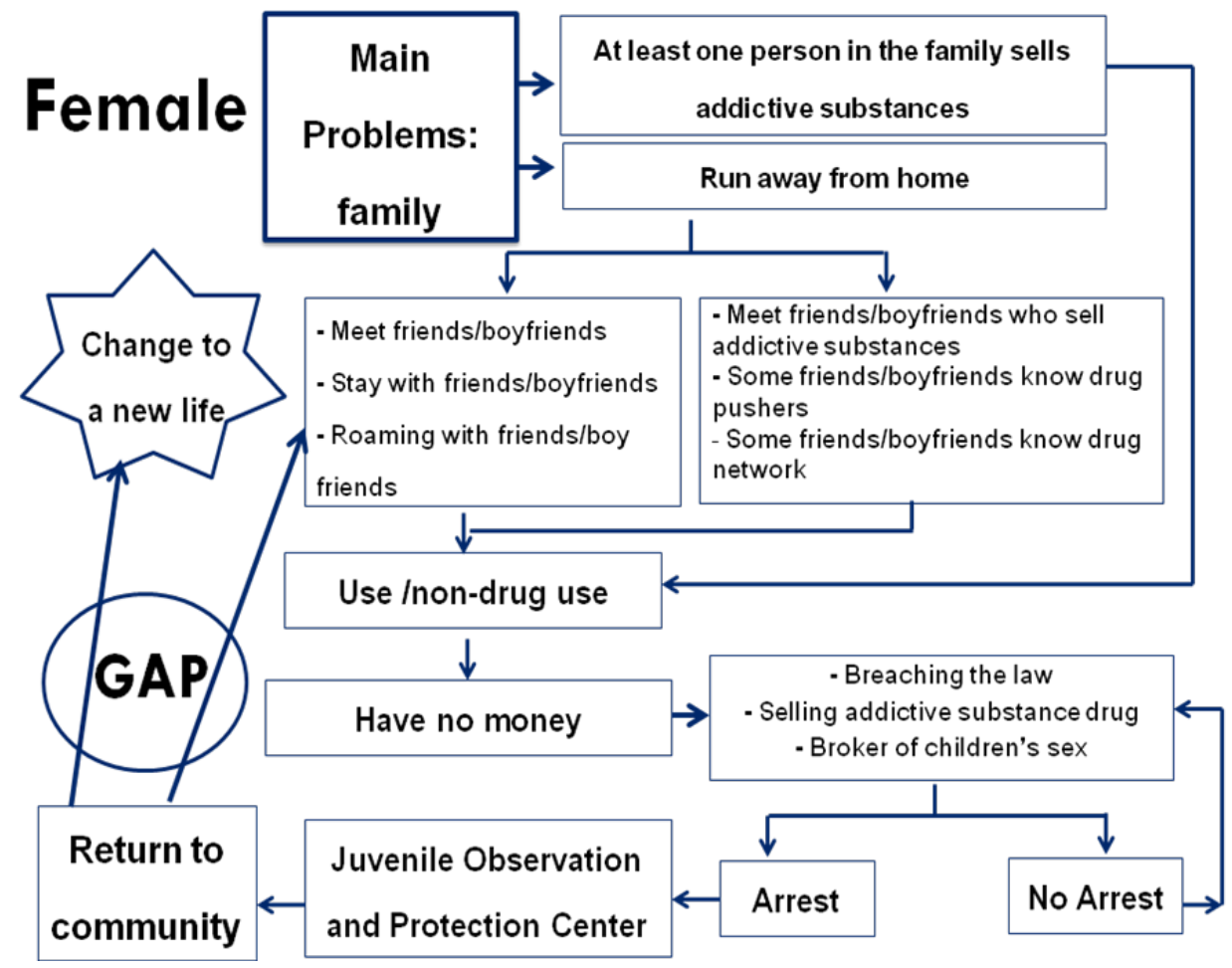

\section{Female juvenile examples}

"F1" - A 17-year-old, whose hometown is in a province in the Central region, completed grade 3, and was charged with drug possession for distribution (300 tablets). This is her sixth time of being arrested. Her father died and her mother has married again. One of her siblings was charged with drug use and drug dealing and was sent to Mutita Home. She ran away from home and lived with her friends since she was 9 years old because her step-father tried to seduce her. She said, "We quarreled because my step-father popped into my mosquito net at night. I was frightened so I hit him on his nose with a cooking knife. His nose bled and was broken, so my mother cursed me. I ran away from home to stay with my friend when I was 9 years old. I started sniffing glue. I've stayed with my friend until now and have never returned home. I had nothing when I left home. I got 20 baht for each tablet. I didn't mind; I only thought it's nice to have some money." She started sniffing glue, 
Yaba when she was 10 years and started as a sex broker when she was 12 years, "My friend was sleeping because she smoked Yaba a lot. So, I received a phone call for her. Her friend said she wanted a girl for a customer. I tried to wake her up but she wouldn't so I managed it for her. I made an appointment with the girl. She asked for 3,000 baht. I sent her a taxi and shared half with her."

"F2", 19 years old, already completed grade 9 . Her hometown is in a province in the Central region.

Her parents were divorced. Her father visited her sometimes. Her mother is in Australia. She is staying with her father's parents in the Eastern region. Her older brother sold and used Yaba and was sent to the correction center. She had a family problem due to her grandparents' strict raising. When she was 13 years she ran away from home to live with her friends. She said "It's like heaven when I first left home. I could do whatever I wanted. A year later, I started to sell drugs because I couldn't live and eat with my friend all the time if I didn't have money. If you were me, you'll know there're a lot of people using drugs. You live in the day world contrary to my night world. I see all the people from the same world. Just close your eyes and you'll see the difference. It's not good but I have no choice". She started first smoking cigarettes and then stuffed it with cannabis. She used Yaba, ecstasy, ketamine and Ice.

"F3"- An 18-year-old, lived in Bangkok. She was dismissed from school when she was in grade 9. Her father died and she lived with her mother and relatives. Her first boyfriend threatened her not to break up with him or else he would tell her mother that they had an affair. When she was 15 years she started smoking cigarettes, followed by stuffing it with cannabis because her friends persuaded her. Her ex-boyfriend persuaded her to try Yaba. She stopped it when she broke up with him and started again when she was 1617 years old. Her new boyfriend asked her to try Ice. "I was stressful then because I quarreled with my ex-boyfriend. I took Yaba followed by Ice and it made me nauseate because all Ice could be sucked but Yaba would leave some sediments mixed with Ice and it was very nauseating. Now I had Yaba and Ice".

\section{Conclusion}

Male juvenile delinquency derived from three problems i.e. individual, family and friends. Initially, the juveniles in this study became involved in drug use through curiosity. They spent their night time existence in close proximity to the sex industry and in pubs. Many of them were engaged in violence between rival gangs and engaged in property crime, including robbery. Male and female groups reported similar family problems i.e. broken homes, imprisonment, gambling, drug use and drug peddling. Friends were strong influences for 
drug use and gang membership contributed to criminal involvement. Many had run away from home to be with their friends - starting to enter into a drug trafficking cycle, resulting in being arrested and sent to the correction center. Juveniles, who had entered the correction center after experiences of drug use, will have high risk of drug relapse and re-offence. As mentioned earlier, family problems lead to female juveniles' entering to the circle of addictive substances. Some families were involved drug peddling.

Results of the study were coherent with the risk factors for recidivism in juvenile offenders. They highlighted various family background measures, such as parental anti-social behaviour, absence of the parents or low emotional attachments. ${ }^{16-19}$ Peer group factors are influential to the juveniles such as adolescent novelty-seeking, peer rejection or peer deviance. ${ }^{16}$ Another risk factor lies in an individual, including nature and extent of previous criminal behaviour ${ }^{16-20}$ or personality characteristics, psychopathology, intelligence or substance abuse..$^{20-28}$

According to the problems indicated in the qualitative analysis, male or female juveniles are in the drug circle because they have used at least one addictive substance. Evidence of high risk behaviour, such as alcohol and drug use, problems and delinquency tend to occur simultaneously. ${ }^{29}$

The study among delinquents showed that over $70 \%$ juveniles used Yaba, $70 \%$ reported drug use, and $75 \%$ reported either alcohol or drug use. ${ }^{30}$

Our study had both quantitative and qualitative methods. From a quantitative study alone, we may not comprehend the rationale for drug use problems while the qualitative study has enhanced understanding the root cause of the problems. We selected new cases representing the current substance use situation. However, there are some limitations. First, the study participants were in the correction centers only in Bangkok and the Central region. Thus, the results might not generalise issues of all juveniles in Thailand. Secondly, there was no scientific support to confirm their substance use. Lastly, a small sample size used to detect group differences between males and females. As such, these findings must be considered preliminary and required a larger sample for further research.

Placing the substance users in the correction center may not be the only solution. State sectors/concerned organizations and the community should also cooperate in resolving juveniles' problems, so that they will adjust their attitudes and ways of living before they return to the society. 


\section{References}

1. Hawkins, JD, Catalano, RF, Miller, JY. Risk and protective factors for alcohol and other drug problems in adolescence and early adulthood: Implications for substance abuse prevention. Psychological Bulletin, 1992;112:64-105

2. Jenson, JM. Risk and protective factors for alcohol and other drug use in adolescence. In: Fraser MW, editor. Risk and resiliency in childhood: An ecological perspective Washington, DC. NASW Press; 1997. p 117-139.

3. Williams J, Ayers C, Abbott R, Hawkins J, Catalano, R. Racial differences in risk factors for delinquency and substance use among adolescents. Social Work Research. 1999; 23: 241-256

4. Substance Abuse and Mental Health Services Administration. Results from the 2010 national survey on drug use and health: Summary of national findings. Retrieved from http://www.samhsa.gov/data/ NSDUH/2k10NSDUH/2k10Results.pdf

5. Office of Applied Studies. Results from the 2002 National Survey on Drug Use and Health: National findings. 2003 DHHS Publication No. SMA 033836, NHSDA Series H-22

6. Chassin L. Juvenile justice and substance use. Future of Children. 2008;18: $165-183$

7. McClelland GM, Teplin LA, Abram, KM. Detection and prevalence of substance use among juvenile detainees. 2004 Retrieved from http://ncjrs. gov/pdffiles1/ojjdp/203934.pdf

8. Office of Juvenile Justice and Delinquency Prevention. Drug offense cases in juvenile courts, 1985-2004. Retrieved from http://www.ncjrs.gov/pdffiles1/ ojjdp/fs200803.pdf

9. Information Work Group and Information Technology. Office of System Development of Juristic Work for Children and Juveniles, Correction and Protection of Children and Juveniles Department. Retrieved from http:// www2.djop.moj.go.th/stat/show stat.php? mainstat id $\equiv 19$

10. Addictive Substance Academic Organization Network Administrative Committee. Addictive Substance Use Status 2007 from nationwide household survey. Bangkok Metropolis, Charansanitwong Publication. 2007 December

11. Areesantichai C, Perngparn U. Surrounded Behavior and Additive Substance Involvement of Juveniles : Children and Juveniles in Correction Centre Case. Health Research Journal. 2007;21(2): 155-162 
12. Areesantichai C, Perngparn U. HIV Risk Behavior of Young Delinquents Breaching the Law Related to Addictive Substance in the Central Juvenile Observation and Protection Centres in Thailand. Proceeding of the 2012 National Symposium on Population Studies. 2012 November 22-23 Bangkok, Thailand. 2012. p 43-60

13. Office of the Narcotics Control Board. Part 1, ONCB Bangkok, ABAC Poll and Drug Dependence Research Center, Chulalongkorn University. Addictive Substance Use Status of Juveniles in Bangkok Correction and Protection of Children and Juvenile Centre, Bangkok Metropolis 2551

14. Perngparn U. A Half Period Review of National Plan of AIDS Prevention and Resolution 2002-2005 Drug User Group. Report of Research Project of Institute of Health Research. Chulalongkorn University, 2004

15. Perngparn U, Terawatkul S, Kanat M, Asanangkornchai S. Monitoring the Change of Addictive Substance Problem Condition. A Study of Children and Juveniles in the Correction and Protection of Children and Juveniles. Report of Research Project in Addictive Substance Academic Organization Network Administrative Committee, ONCB. 2003

16. Benda BB, Tollet CL. A study of recidivism of serious and persistent offenders among adolescents. Journal of Criminal Justice 1999; 27: 111-126

17. Conger RD, Neppl T, Kim KJ, Scaramella L. Angry and aggressive behavior across three generations: A prospective, longitudinal study of parents and children. Journal of Abnormal Child Psychology 2003;31: 143-160

18. Barnow S, Lucht M, Freyberger HJ. Correlates of aggressive and delinquent conduct problems in adolescence. Aggressive Behavior 2005;31: 24-39

19. Hoeve M, Blokland A, Dubas JS, Loeber R, Gerris JRM, van der Laan PH. Trajectories of delinquency and parenting styles. Journal of Abnormal Child Psychology 2008;36: 223-235

20. Carcach C, Leverett S. Recidivism among juvenile offenders: an analysis of times to reappearance in court. Australian Institute of Criminology Research and Public Policy Series. 1999 no. 17

21. Loeber R, Farrington DP. Young children who commit crime: Epidemiology, developmental origins, risk factors, early interventions, and policy implications. Development and Psychopathology 2000;12: 737-762.

22. Cottle CC, Lee RJ, Heilbrun K. The prediction of criminal recidivism in juveniles: A meta-analysis. Criminal Justice and Behavior 2001;28: $367-$ 394 
23. Duncan SC, Duncan TE, Strycker LA. Qualitative and quantitative shifts in adolescent problem behavior development: A cohort-sequential multivariate latent growth modeling approach. Journal of Psychopathology and Behavioral Assessment 2001;23: 43-50

24. Huang B, White HR, Kosterman R, Catalano RF, Hawkins JD. Developmental associations between alcohol and interpersonal aggression during adolescence. Journal of Research in Crime and Delinquency 2001;38: 64-83

25. Vermeiren R, de Clippele A, Schwab-Stone M, Ruchkin V, Deboutte, D. Neuropsychological characteristics of three subgroups of Flemish delinquent adolescents. Neuropsychology 2002;16: 49-55

26. Chang JJ, Chen JJ, Brownson RC. The role of repeat victimization in adolescent delinquent behaviors and recidivism. Journal of Adolescent Health 2003;32: 272-280

27. van Dam C, Janssens JMAM, De Bruyn EE. PEN, Big Five, juvenile delinquency and criminal recidivism. Personality and Individual Differences 2004;39: 7-19

28. Lattimore PK, Macdonald JM, Piquero AR, Linster RL, Visher CA. Studying the characteristics of arrest frequency among paroled youthful offenders. Journal of Research in Crime and Delinquency 2004;41: 37-57

29. Dembo R, Schmeidler J. Family empowerment intervention: An innovative service for high-risk youths and their families. Binghamton, NY: Haworth Press; 2002

30. National Center on Addiction and Abuse Substance. Final Report to the National Institute of Justice. Trends in substance use and treatment needs among inmates. New York, NY: The National Center on Addiction and Substance Abuse at Columbia University; 2002 